\title{
Doctor-patient communication in a culturally hierarchical context of Southeast Asia : a partnership approach
}

Citation for published version (APA):

Claramita, M. (2012). Doctor-patient communication in a culturally hierarchical context of Southeast Asia : a partnership approach. [Doctoral Thesis, Maastricht University]. Maastricht University. https://doi.org/10.26481/dis.20120330mc

Document status and date:

Published: 01/01/2012

DOI:

10.26481/dis.20120330mc

Document Version:

Publisher's PDF, also known as Version of record

\section{Please check the document version of this publication:}

- A submitted manuscript is the version of the article upon submission and before peer-review. There can be important differences between the submitted version and the official published version of record.

People interested in the research are advised to contact the author for the final version of the publication, or visit the DOI to the publisher's website.

- The final author version and the galley proof are versions of the publication after peer review.

- The final published version features the final layout of the paper including the volume, issue and page numbers.

Link to publication

\footnotetext{
General rights rights.

- You may freely distribute the URL identifying the publication in the public portal. please follow below link for the End User Agreement:

www.umlib.nl/taverne-license

Take down policy

If you believe that this document breaches copyright please contact us at:

repository@maastrichtuniversity.nl

providing details and we will investigate your claim.
}

Copyright and moral rights for the publications made accessible in the public portal are retained by the authors and/or other copyright owners and it is a condition of accessing publications that users recognise and abide by the legal requirements associated with these

- Users may download and print one copy of any publication from the public portal for the purpose of private study or research.

- You may not further distribute the material or use it for any profit-making activity or commercial gain

If the publication is distributed under the terms of Article $25 \mathrm{fa}$ of the Dutch Copyright Act, indicated by the "Taverne" license above, 


\title{
Doctor-patient communication in a culturally hierarchical context of Southeast Asia: A partnership approach
}

\author{
DISSERTATION
}

to obtain the degree of Doctor at Maastricht University, on the authority of the Rector Magnificus Prof. Dr. G. P. M. F. Mols, in accordance with the decision of the Board of Deans, to be defended in public at The Aula, on 30 March 2012 at 14.00 hours

by

Mora Claramita, MD, MHPE 


\section{Promoters}

Prof. Dr. C.P.M. van der Vleuten - Maastricht University

Prof. Dr. Hardyanto Soebono, MD - Gadjah Mada University

\section{Co-promotor}

Dr. Jan van Dalen - Maastricht University

\section{Reading committee members}

Prof. Dr. Arie Nieuwenhuijzen Kruseman, MD - Maastricht University

Prof. Dr. Gerda Croiset, MD - VU University Medical Center Amsterdam

Prof. Dr. Janke Cohen-Schotanus - Rijkuniversiteit Gronigen

Prof. Job Metsemakers, MD - Maastricht University

Prof. Dr. Albert J.J. Scherpbier, MD - Maastricht University 
The study in this dissertation was carried out at

\section{Maastricht University im Lammun!}

in the School of Health Professions Education

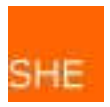

in collaboration with Gadjah Mada University (UGM)

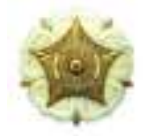

Funded by:

NPT Project - UM-UGM 2007-2011

\section{The story behind the picture of Karina and Farrah on a seesaw}

The picture on the cover of this dissertation was created to illustrate partnership interaction between family members in a culturally hierarchical context in Southeast Asia. Based on the literature and on my studies, I have come to the conclusion that a partnership communication style should preferably be learned from very early in life in the communication between older and younger brothers and sisters within a family - before this style can be extended to the interaction between parents and children, senior and junior colleagues, chairman and employees, and doctors and patients. The picture shows my elder daughter making an effort to keep the seesaw straight despite the differences in weight between the two sisters. She has dropped one of her slippers, keeping her other foot firmly on the ground to maintain an even balance. From a partnership perspective, her effort can be interpreted as an invitation from the (older) sister, who is higher in the social-hierarchy, to the younger sister to engage in an equal relationship.

My younger daughter is wearing the traditional costume of Aceh and the elder one is wearing a Javanese costume. In this way they are representing different ethnic groups in Indonesia, Southeast Asia. In Indonesia, a perfect time to dress young-ladies up in traditional costume is on $21^{\text {st }}$ April - the birthday of Princess Kartini from mid-Java. Early in the 20th century Princess Kartini wrote a book in which she put forward ideas about partnership education for males and females. It is therefore very appropriate that this picture was taken in April 2011.

\section{Mora Claramita, Yogyakarta 2012}

Layout: B. Zurkurniyanti and F. Ediningtyas

Cover design: M. Claramita and Endaryanto

Production: Tiara Wacana

ISBN: 978-602-19549-5-9 


\section{Contents}

Chapter 1: Introduction

Chapter 2: The current doctor-patient communication in Southeast Asian context: An adapted Western communication guideline did not work-out well

Claramita M and Majoor G. Educ Health 2006; 19(3): 308-320

Chapter 3: The current doctor-patient communication in Southeast Asian context: The conflict between ideal and reality

Claramita M, Utarini A, Soebono H, van Dalen J, van der Vleuten C. Adv Health Sci Educ 2011; 16(1): 68-80

Chapter 4: The current doctor-patient communication in Southeast Asian

context: Doctors communicate sub-optimally regardless of patients' educational background

Claramita M, van Dalen J, van der Vleuten C. Pat Educ Couns 2011; 85 (3): e169-e174

Chapter 5: Doctor-patient communication in Southeast Asia: A different culture?

Claramita M, Nugraheni MDF, van Dalen J, van der Vleuten C. Adv Health Sci Educ 2012; DOI 10.1007/s10459-012-9352-5

Chapter 6: Doctor-patient communication guideline that is tailored to Southeast Asian context

Claramita M, Prabandari YS, van Dalen J, van der Vleuten C. Southeast As J Med Educ 2010; 4 (2): 23-30

Chapter 7: The introduction of a partnership style doctor-patient communication guideline to senior medical teachers in a culturally hierarchical context

Chapter 8: General Discussion

Summary (English)

Samenvatting (Dutch)

Appendix

Acknowledgment

Curriculum Vitae

SHE Dissertations Series 
Chapter 1

Introduction 


\section{The prime tasks of a health care provider}

For many centuries, people in different parts of the world who were responsible for helping the sick were trained to identify the nature of a patient's problem and to choose the correct healing remedy or healing action ${ }^{1-4}$. With the arrival of modern medicine the concepts of diagnosis and treatment came into use. "Diagnosis" means discerning, distinguishing, and is derived from Greek dia, meaning apart and gignoskein meaning to learn to know, while healing processes are designated by the term "treatment" from the Greek word therapeuein meaning to cure, to treat ${ }^{4}$. The Latin phrase Ars Medicina refers literally to the medical art, denoting any effort to help improve the health of patients ${ }^{5}$.

In the present era, traditional healers use different terms and approaches in relation to "diagnosis" and "treatment" compared to doctors trained in modern medicine. However, the two stages of identifying the problem and determining the most appropriate treatment which can be discerned in health provider-patient consultations are equally fundamental to healing procedures used in traditional medicine to help one of the community members recover from illness ${ }^{6}$. There appears to be agreement between ancient healers, modern medical doctors and today's traditional healers that the prime tasks of a health professional are to find out what the problem of the ill person is and subsequently make every effort to resolve the patient's health problem (the treatment).

In the previous century medical education began to fathom that the fundamental tasks of a health professional (diagnosis and treatment) were carried out within an interaction process between health provider and patient ${ }^{7-10}$. The diagnosis is basically obtained by interviewing and, if appropriate, examining patients in a process encompassing history taking, physical examination, diagnosis, and treatment or management plan. It was realized that communication plays a role in eliciting the patient's problem, explaining the diagnosis to patients and in gaining patients' agreement and cooperation with the proposed treatment. Communication thus continues throughout the consultation, from the moment the doctor greets the patient, during exploration of the problem, and at the close of the consultation; it may even continue outside the doctors' consultation room. On top of these insights into the role of communication, social cultural studies revealed that a learning process occurs when individuals interact with their environment ${ }^{11}$. It is therefore important that health professionals should not focus exclusively on diagnosis and treatment when communicating with patients. Patients' perceptions of their illness and their 
social cultural background are also likely to influence the diagnostic process and the success of treatment ${ }^{12}$. During their studies, health professionals should not only learn about diseases, they should also study the people who come to them with their illnesses. Consequently, learning medicine needs to include learning about interaction processes ${ }^{12-14}$. These insights about the crucial role of the interaction between medical students or young doctors and their patients led to the view of communication skills as an important issue in medical education.

\section{The importance of acknowledging the patient's story}

The first important study of interaction in small groups was initiated by Robert Bales, a social psychologist, who in the 1950s conducted an interaction process study in Harvard, US. He identified a task oriented and a social interaction style during group interaction $^{15}$. One of the first observational studies of the interaction during health provider-patient consultations was carried out by Michael Balint, a physician, in the United Kingdom in $1957^{16}$. Balint started out by observing his father (who was a medical doctor) and his patients, paying special attention to the process of their interaction. Both Bale's and Balint's studies inspired many seminal studies of doctorpatient communication skills. Based on Michael Balint's studies among general practitioners in London, his wife, Enid Balint, investigated the possibilities of patientcentered care $^{17}$. This led to the Balint Group, a group of practitioners who meet to discuss communication aspects of clinical cases. Even today, many physicians in different parts of the world continue to participate in such groups. Bale's studies stimulated a series of fundamental studies of health provider- patient interaction by Roter and her team ${ }^{18,19}$. In the late 1970s, there was increasing awareness that information given by the patient during a consultation could contribute to the diagnosis $^{20}$. This implied that failure to consider the patient's story could affect the fundamental consultation process: diagnosis and treatment. It also meant that the successful outcome of consultations with patients who were able to tell their own story or share their health problems (e.g. in non-emergency situations) depended on the doctor's skill in eliciting, understanding and taking into account the patients' story. From this viewpoint, adequate communication skills came to be seen as essential for medical doctors.

During consultations, communication starts when the doctor explores why the patient has come to see him or her, and continues with exploration of the patient's feelings and expectations, and of his/her perceptions regarding the impact of the problem on his/her life. Doctors' ability to explore patients' perceptions (including verbal and non 
verbal behavior) is vital to this process. Exploration is followed by a structured history (review of organ systems), in which the doctor works towards a diagnosis ${ }^{9,10}$. Communication with the patient continues during physical examination to build mutual trust and to explore the patient's problem more comprehensively. Communication does not stop once the diagnosis is established, but continues when the diagnosis is explained and the treatment or management plan discussed. Agreement between doctor and patient has been shown to further patient compliance with treatment. Because of this crucial role of communication during consultations, communicating with patients was included among the clinical skills to be mastered by medical students and young doctors ${ }^{12-14}$.

\section{Generic doctor-patient communication guidelines from Western cultures}

Based on the above-described growing realization of the key function of doctor patient communication, generic doctor-patient communication guidelines were developed. In the UK, there was general consensus that the Calgary-Cambridge Observation Guide was the most comprehensive guideline for doctor-patient communication skills ${ }^{8-10}$. In the US, several guidelines are in use, such as the Segue Framework ${ }^{21}$, The Four Habits Model $^{22}$, The Comrade ${ }^{23}$ and the Provider-Patient Orientation Scale ${ }^{24}$. Roter developed Roter Interaction Process Analysis (RIAS), which has been used to analyze millions of health provider-patient consultations around the world, in both Western ${ }^{18,19}$ and nonWestern settings ${ }^{25,26}$, including a study by Kim in Indonesia ${ }^{27}$. As a result of these developments, medical education today teaches students to pay attention to patients' stories, their feelings and expectations, and young doctors are trained to work together with their patients to improve their patients' health ${ }^{28}$.

\section{The continuum of doctor-patient communication styles}

A continuum can be observed in doctor-patient communication styles ${ }^{29-31}$. It ranges from the paternalistic style, with maximal contribution from the doctor and minimal contribution from the patient to clinical decision making, to the consumerism style where the amounts of doctor and patient contribution are reversed ${ }^{32}$. In between, there is the style with equal contributions from doctors and patients, characterized by mutual understanding and partnership between doctor and patient (the partnership style of doctor-patient communication). Communication skills for informed and shared decision making are fundamental to this style ${ }^{33}$. 


\section{The Southeast Asian Context}

Most doctor-patient communication guidelines originated from studies in Western contexts. These guidelines tend to favor the partnership style centered around informed and shared decision making. In the context of Southeast Asian cultures, however, the doctor-patient relationship may be different due to the culturally determined strong social hierarchy in which all interaction patterns are determined by the different positions of older and younger people, parents and children, teachers and students, chairman and employees. Social hierarchy inevitably has an effect on the doctor-patient relationship ${ }^{34}$. The hierarchical distance between Southeast Asian doctors and patients, in a culture where very subtle, polite and most of the time nonverbal communication is valued, appears to be a barrier to the type of communication promoted by the Western guidelines, which presume an open exchange of ideas and equal contribution to the communication ${ }^{35-38}$. Southeast Asians are also less used to individual autonomy in clinical decision-making compared to Westerners. The patient's family or the community of which the patient is a member can have a greater say in clinical decisions than patients themselves. Another difference is the status of traditional medicine, which plays an important role in health care. People in Southeast Asia tend to use various kinds of traditional alternative medicines, such as herbs, massages, and other methods that are logical to local perceptions. As a result, traditional healers can be more influential than medical doctors educated in modern, science-based medicine ${ }^{6}$.

Apart from the strong social hierarchy and the role of the community and traditional medicine, doctor-patient communication is affected by the educational gap between doctors and patients. In Indonesia, for example, which is the fourth most densely populated country in the world, over half of the population have had no formal education beyond primary school level ${ }^{39}$. As a result, the educational gap between doctors and patients can have a detrimental effect on their communication ${ }^{27}$. The above mentioned factors - social hierarchy, a communal society, a communication pattern characterized by subtle, non-verbal politeness, the tendency to prefer traditional medicine to western medicine, and the educational gap between doctor and patient - have caused doctor-patient communication to move to the paternalistic end of the communication continuum. Consequently, generic doctor-patient communication guidelines developed in Western contexts need modification if they are to be effective in the Southeast Asian context ${ }^{40}$. 


\section{Limited doctor-patient interaction guidelines in Southeast}

\section{Asian context}

Several studies of doctor-patient communication have been conducted in the Asian context. Kim (2003) used the RIAS method to study the doctor-patient relationship in a family planning program in Indonesia. She found that patients were hesitant to ask questions due to the educational gap between health professionals and patients ${ }^{27}$. Moore (2008 and 2009) investigated the doctor-patient relationship in Nepal, using the Patient Practitioner Orientation Scale (PPOS), and found that for Nepalese patients it was more important to have a caring doctor than a doctor who shared information with them ${ }^{41,42}$. In line with Moore's study, Lee conducted a cohort study among medical students in Singapore using the PPOS. He found that students in Singapore had lower PPOS scores than their US counterparts ${ }^{43}$. In Japan, Ohtaki (2003) analyzed differences in doctor-patient interaction between the US and Japan. He found differences in the total time of consultations and the proportion of time spent on each phase of the consultation, with overall duration being longer in the US, whereas in Japan pauses and interruptions were longer and back-channel responses or silenceresponse more frequent. This suggests that non-verbal interaction plays a stronger role in Japan than in the US $^{44}$. Iragiliati from Indonesia (2006) investigated how during patient education medical doctors should greet their Southeast Asian patients properly and how medical doctors should act as if they were a member of the patient's family ${ }^{45}$. Chan (2003) and Ming Jung Ho (2008) in Taiwan studied communication skills training for Asian students, and found that adequate training led to significantly better results $^{46,47}$.

\section{Research Questions}

Studies on doctor-patient communication in both Western and non-Western contexts (including Southeast Asia) have explored many problems in doctor-patient communication. However, they have not resulted in clear guidelines for doctor-patient communication that were especially designed to meet requirements for Southeast Asian settings. It also remains to be elucidated how generic guidelines for communicating with patients, developed in Western contexts, can be used in Southeast Asian contexts. It is therefore urgent to investigate what would be an appropriate approach to doctor-patient communication that fits with Southeast Asian culture. In this dissertation studies are described that investigated how a generic doctor-patient communication guideline, developed for a Western context, could be 
applied effectively within a Southeast Asian context with its different cultural characteristics. The studies addressed four research questions:

1. What is the current doctor-patient communication style in a Southeast Asian context?

2. What are doctors' and patients' perceptions regarding the current generic doctorpatient communication guideline, which emphasizes the partnership consultation style?

3. What kind of doctor-patient communication guideline would seem more suitable for patients in a Southeast Asian context?

4. How can a doctor-patient communication guideline tailored to Southeast Asian culture be introduced to medical teachers in that context?

The studies presented in chapters 2, 3 and 4 deal with research question 1, exploring the current situation of doctor-patient communication in Southeast Asia using different methods of observations and interviews. Chapter 5 deals with research question 2, and describes a study in which grounded theory methodology was used to gain insight into doctors' and patients' cultural perceptions. Chapter 6 concerns research question 4 , and describes a study aimed at developing and validating a doctor-patient communication guideline that is tailored to a Southeast Asian context. Chapter 7 investigates how medical teachers in a Southeast Asian culture can be trained to use a communication guideline that has been validated for that context. Chapter 8 discusses the main findings and the strengths and limitations of the various studies, and makes recommendations for further studies and educational approaches to doctor-patient communication skills. 


\section{References}

1. Horstmanshoff HFJ and Stol M. Magic and Rationality in Ancient Near Eastern and GrecoRoman Medicine. Boston: Brill Publishers, 2004.

2. Syed Ibrahim B. Islamic Medicine: 1000 years ahead of its times. Journal of the Islamic Medical Association 2002;2:2-9.

3. Castiglioni A. A History of Medicine. New York: J Aronson, 1975.

4. Porter R. The Greatest Benefit to Mankind: A Medical History of Humanity from Antiquity to the Present. London: Harper Collins, 1997.

5. Dorland. Dorland's Medical Dictionary. $30^{\text {th }}$ Ed. Anderson, D. (Editor). Philadelphia: Saunders Co., 2003.

6. Helman CG. Culture, Health and IIIness. Oxford: Butterworth-Heinemann, 1994.

7. Roter D and Larson S. The Roter interaction analysis system [RIAS]: Utility and flexibility for analysis of medical interaction. Patient Education and Counseling 2002;46:243-251.

8. Hall JA, Roter DL, and Katz NR. Meta-analysis of correlates of provider behavior in medical encounters. Medical Care 1988;26(7):657-675.

9. Kurtz S, Silverman J, and Draper J. Teaching and Learning Communication Skills in Medicine. Oxon: Radcliffe Medical Press, 2002.

10. Silverman J, Kurtz S, and Draper J. Skills in Communicating with Patients. Oxon: Radcliffe Medical Press, 2002.

11. Wrestch JV. Voices of the Minds: A Socio Cultural Approaches to Mediated Actions. Massachusetts: Harvard Univ Press, 1993.

12. Whitcomb ME. Communication and professionalism. Patient Education and Counseling 2000; 41:137-144.

13. Brown Jo. How clinical communication has become a core part of medical education in the UK. Medical Education;42:271-278.

14. Makoul $G$ and Schofield T. Communication teaching and assessment in medical education: an international consensus statement. Patient Education and Counseling 1999;137:191195.

15. Bales RF. Interaction Process Analysis: A Method for the Study of Small Groups. Cambridge, Mass: Addison-Wesley, 1950.

16. Balint M. The Doctor, His patients and The Illness. London: Churchill Livingstone, 1957.

17. Balint E. The possibilities of patient centered in medicine. Lectures and Addresses. J Royal College General Practice 1969;17:269-276.

18. Mead $\mathrm{N}$ and Bower P. Measuring patient centeredness: A comparison of three observation- based instruments. Patient Education and Counseling 2000;39:71-80.

19. Roter DL, Stewart M, Putnam SM, Lipkin Jr M, Stiles W, and Inui TS. Communication patterns of primary care physicians. J Am Med 1997;277:350-356.

20. Bickley LS, Szilagyi PG, and Bates B. Bates' guide to physical examination and history taking. Philadelphia: Lippincot William\&Wilkins, 2007.

21. Makoul G. The SEGUE framework for teaching and assessing communication skills. Patient Education and Counseling 2001;45:23-34.

22. Frankel RM and Stein T. Getting the most out of the clinical encounter: The four habits model. Permanente Journal, Fall 1999;3(3):79-88.

23. Edward A, Elwyn G, Hood K, et al. The development of COMRADE - patient based outcome measure to evaluate the effectiveness of risk communication and treatment decision making in consultation. Patient Education and Counseling 2003;50:311-322. 
24. Krupat E, Hiam M, Fleming MZ, and Freeman P. Patient-centeredness and its correlates among first year medical students. International Journal of Psychiatry Medicin 1999;3(29):347-356.

25. Abdel-Thawab $\mathrm{N}$ and Roter $\mathrm{D}$. The relevance of client-centered communication to family planning settings in developing countries: Lesson from the Egyptian experience. Social Science \& Medicine 2002;54:1357-1368.

26. Kim YM, Kols A, Mwarogo P, and Awasum D. Differences counseling men and women: family planning in Kenya. Patient Education and Counseling 2000; 39:37-47.

27. Kim YM, Putjuk F, Basuki E, and Kool A. Increasing patient participation in reproductive health consultation: An evaluation of smart patient coaching in Indonesia. Patient Education and Counseling 2003;50:113-122.

28. Carracio C, Susan D, Wolfsthal SD, Englander R, Ferentz K, and Martin C. Shifting Paradigms: From Flexner to Competencies. Academic Medicine 2002;77:361-367.

29. Charles $C$, Whelan $T$, and Gafni A. Shared decision making in the medical encounter: what does it mean? (Or it takes two to tango). Social Science Medicine 1997;44:681-692.

30. Charles $C$, Whelan $T$, and Gafni A. What do we mean by partnership in making decisions about treatment? BMJ 1999;319:780-782.

31. Makoul $G$ and Clayman ML. An integrative model of shared decision making in medical encounters. Patient Education and Counseling 2006;60:301-312.

32. Bensing JM, Tromp F, van Dulmen S, van den Brink-Muinen A, Verheul W, and Schellevis FG. Shifts in doctor-patient communication between 1986 and 2002: a study of videotaped General Practice consultations with hypertension patients. BMC FamPract 2006;7:62.

33. Thistlethwaite JE and van der Vleuten CPM. Informed shared decision making: view and competencies of pre-regristation house officers in hospital and general practice. Educ Prim Care 2004;15:83-92.

34. Hofstede G. Culture's Consequences, Comparing Values, Behaviors, Institutions, and Organizations across Nations. Newbury Park, CA: Sage Publications, 2003.

35. Geertz C. The Religion of Java. Chicago and London: The University Chicago Press, 1976.

36. Geertz C. The Java Family. Jakarta: GrafitiPress, 1983.

37. Raelin JA. Workbased Learning: The new frontier of management development. New Jersey: Prentice Hall, 2000.

38. Galanti GA. Caring for Patients. Philadelphia: University of Pennsylvania Press, 2008.

39. Board Statistic Centre of Indonesia. Indonesian Labor Situation - Official Statistic. No. 33/05/Th. XIII, 10 Mei 2010. Jakarta, Indonesia; 2010.

40. Von Fragstein M, Silverman J, Cushing A, Quilligan S, Salisbury $H$, and Wiskin C. UK consensus statement on the content of communication curricula in undergraduate medical education. Medical Education 2008;42(11):1100-7.

41. Moore M. What does patient-centered communication mean in Nepal? Medical Education 2008;42:18-26.

42. Moore M. What do Nepalese medical students and doctors think about patient-centered communication? Patient Education and Counseling 2009;76:38-43.

43. Lee KH, Seuw A, Luo N, and Koh D. Attitudes towards the doctor-patient relationship, a prospective study in an Asian Medical School. Medical Education 2008;42:1092-1099.

44. Ohtaki S, Ohtaki T, and Fetters MD. Doctor-patient communication: A comparison between USA and Japan. Family Practice 2003;20(3):276-283.

45. Iragiliati ES. Utterance Patterns and Politeness Strategies in Indonesian Medical Discourse. A doctoral dissertation submitted to Graduate School of State University Malang. Chicago: ProQuestInternational, 2006 
46. Chan CSY, Wun YT, and Cheung A. Communication skills of General Practitioners: Any room for improvement? How much can be improved? JME 2003;37:514-526.

47. Ming-Jung Ho, Greece Y, Ken LL, Mary CB, and Alexander AG. Cross Cultural medical education: Can patient centered cultural competencies training be Effective in Nonwestern countries? Medical Teacher 2008;30:719-721. 


\section{Chapter 2}

\section{The current doctor-patient communication style in a Southeast Asian context:}

An adapted Western communication guideline did not work out well

A study conducted in an Indonesian teaching hospital to compare the communication styles of graduates of a problem-based curriculum (trained in communication skills using a Western guideline) and graduates of a non-problembased curriculum (untrained in communication skills).

A full text version was published as:

Claramita M and Majoor G. Comparison of communication skills in medical residents with and without communication skills training as provided by Faculty of Medicine Gadjah Mada University. Education for Health 2006; 19 (3): 308-320. 


\section{Abstract}

Objective: To promote better doctor-patient relationships in clinical practice, many medical faculties have introduced practical communication skills training programs for their students. This study is aimed at comparing the communication skills of graduates of the Faculty of Medicine of Gadjah Mada University, Indonesia, educated with and without communication skills training as perceived by their patients and by the graduates themselves.

Methods: Over 300 patients were seen by 18 medical residents trained in communication skills before graduation and 30 residents who had not attended this training. After consultation patients and residents completed a 39-item questionnaire addressing the doctor's communication behavior skills. In the questionnaires completed by patients the desired communication behavior of doctors was also rated.

Results: Patients did not observe any differences in communication behavior skills among residents who received training and those who did not. These two groups of trained and non-trained residents assessed their own communication behavior skills. On 4/39 questionnaire items patients rated the communication behavior skills of trained residents lower than the residents themselves and the ratio was 13/39 for nontrained residents. A significant gap was noted between doctors' communication behavior skills as observed and desired by their patients ( $p$ 50.001).

Conclusions: Undergraduate communication skills training in the institution under study could not be demonstrated to illustrate a difference in the communication behavior skills of its graduates from graduates from the same institution who did not attend commu-nication skills training. Trained graduates, however, were more aware of communication behavior skills as being preferred by their patients than their peers who were not trained in communication behavior skills training during their undergraduate studies. 


\section{Chapter 3}

\section{The current doctor-patient communication style in a Southeast Asian context:}

The conflict between ideal and reality

Communication style was observed by medical students during consultations of internal medicine residents with patients with different educational backgrounds in an Indonesian teaching hospital. In-depth interviews about communication were conducted with patients, residents and students.

A full text version was published as:

Claramita M, Utarini A, Soebono H, van Dalen J, van der Vleuten C. Doctor-patient communication in a Southeast Asian setting: the conflict between ideal and reality. Advances Health Sciences Education 2011; 16 (1): 69-80. 


\section{Abstract}

Introduction: Doctor-patient communication has been extensively studied in nonWestern contexts and in relation to patients' cultural and education backgrounds. This study explores the perceived ideal communication style for doctor-patient consultations and the reality of actual practice in a Southeast Asian context.

Methods: We conducted the study in a teaching hospital in Indonesia, using a qualitative and a quantitative design. In-depth interviews were conducted with ten internal medicine specialists, ten internal medicine residents, sixteen patients in two groups based on education level and ten most senior medical students. The contributions of doctors and patients to the communication during consultations were observed and rated quantitatively by thirty internal medicine residents, 393 patients with different educational backgrounds and ten senior medical students. The 'informed and shared decision making' is the central observation in this quantitative study.

Results: The results of the interviews showed that Southeast Asian stakeholders are in favor of a partnership style of communication and revealed barriers to achieving this: doctors and patients are not prepared for a participatory style and high patient load due to an inefficient health care system does not allow sufficient time for this type of communication. The results of the quantitative study showed a sharp contrast between observed and ideal communication styles. A paternalistic style seems to prevail, irrespective of patients' educational background.

Discussion and Conclusion: We found a sharp conflict between ideal and reality concerning doctor-patient communication in a Southeast Asian context. Further studies should examine ways to change the prevailing communication style in the desired direction. 


\section{Chapter 4}

\section{The current doctor-patient communication style in a Southeast Asian context:}

Doctors communicate sub-optimally regardless of patients' educational background

Observation study to analyze communication style during consultations of internal medicine residents and patients with high and low levels of education using the Roter Interaction Analysis System (RIAS).

A full text version was published as:

Claramita M, van Dalen J, van der Vleuten CPM. South East Asian doctors and patients are not approaching their perceived ideal partnership style of consultation. Patient Education and Counseling 2011; 85(3): e169-e174. 


\section{Abstract}

Background: The Roter Interaction Analysis System (RIAS) is widely used to analyze doctor-patient communication in both Western and non-Western settings, including Southeast Asia. Studies in both settings show that patients are more satisfied with doctor-patient communication when the consultation style approaches a partnership model. In Western contexts this consultation style has been shown to be positively related to patients' educational background. This relationship has not been explored in Southeast Asian contexts.

Objective: To explore the relationship between the style of doctor-patient communication and patients' educational background in a Southeast Asian setting.

Method: We analyzed a total of 245 audio-taped consultations involving 30 internal medicine residents with 7-10 patients each. The patients were categorized into a group with a high and a group with a low educational level. We used RIAS to analyze the data and ranked 41 RIAS utterances and RIAS-based composite categories in order of observed frequency during consultations.

Results: The residents invariantly used a paternalistic style irrespective of patients' educational background. The composite categories and the RIAS utterances show no significant relationship between communication style and patients' educational level.

Conclusion: Doctors in a Southeast Asian country use a paternalistic communication style during consultations, regardless of patients' educational background. 


\section{Chapter 5}

\section{Doctor-patient communication in Southeast Asia:}

A different culture?

A study using grounded theory methodology to explore emergent cultural characteristics that are relevant to doctor-patient communication in a Southeast Asian context.

A full text version was published as:

Claramita M, Nugraheni MDF, van Dalen J, van der Vleuten C. Advances in Health Sciencies Education 2012; DOI 10.1007/s10459-012-9352-5 


\section{Abstract}

Introduction: Studies of doctor-patient communication generally advocate a partnership communication style. However, in Southeast Asian settings, we often see a more one-way style with little input from the patient. We investigated factors underlying the use of a one-way consultation style by doctors in a Southeast Asian setting.

Method: We conducted a qualitative study based on principles of grounded theory. Twenty residents and specialists and twenty patients of a low or high educational level were interviewed in internal medicine outpatient clinics of an Indonesian teaching hospital and two affiliated hospitals. During 26 weeks we engaged in an iterative interview and coding process to identify emergent factors.

Results: Patients were generally dissatisfied with doctors' communication style. The doctors indicated that they did not deliberately use a one-way style. Communication style appeared to be associated with characteristics of Southeast Asian culture, the health care setting and medical education.

Discussion and Conclusion: Doctor-patient communication appeared to be affected by cultural characteristics which fell into two broad categories representing key features of Southeast Asian culture, "social distance" and "closeness of relationships", and to characteristics categorized as "specific clinical context". Consideration of these characteristics could be helpful in promoting the use of a partnership communication style. 


\section{Chapter 6}

\section{A doctor-patient communication guideline that is tailored to patients in a Southeast Asian context}

A study describing the development and validation of a communication guideline for doctor-patient communication in a Southeast Asian context.

A full text version was published as:

Claramita M, Prabandari Y, van Dalen J, van der Vleuten CPM. A guideline for doctorpatient communication more appropriate in South East Asia. Paper published in Southeast Asia Journal of Medical Educatio 2010; 4 (2): 23-30. 


\section{Abstract}

Introduction: In Southeast Asia there is a big gap between the partnership style now desired by patients and the reality of actual practice, which reflects a more paternalistic style. Asian culture, with its hierarchical social system, less autonomy for members of society and less verbally explicit communication style contributes to this difference. This paper describes the development and validation of a guideline to help doctors in the context of the study to become more patient-centered.

Method: To develop a guideline, we triangulated results from previous studies on doctor-patient communication with in-depth interviews with communication skills teachers at an Indonesian School of Medicine. To validate the guideline, we interviewed international experts who had conducted research on this subject in an Asian context.

Results: Southeast Asian patients expect more partnership in their consultations. In this respect they do not differ from Western patients. Three other distinct issues emerged from the data. Firstly, the social and cultural context of their communities is very important for Southeast Asian patients compared with patients from the West who, on the whole have more autonomy. Secondly, much of the communication expressed by patients and their families with doctors is non-verbal compared with Western patients. Thirdly, traditional medicine still holds an important place.

Conclusion: There is a shifting paradigm towards partnership communication during doctor-patient consultations in Southeast Asian context. Our guideline identifies the skills needed to consult effectively and details what needs to be taught to young doctors in order to enhance their responsiveness to Southeast Asian patients. It builds on Western models of the consultation enriched with contextual examples. 


\section{Chapter 7}

\section{The introduction of a partnership style doctor- patient communication guideline to senior medical teachers in a culturally hierarchical context}

A participatory study involving 6 stages within 18 months.

Part of this paper is under editorial review 


\begin{abstract}
Objectives: Despite the strong hierarchical culture which holds a more one-way communication style the Southeast Asian context, a guideline of partnership doctorpatient communication was established and needs to be introduced to medical teachers. Considering that the junior researchers are at the lower level of hierarchy than the teachers, we used a participative way to introduce the guideline. This study aims to explore to what extent this approach can be used in a culturally hierarchical context.
\end{abstract}

Methods: Three junior researchers invited 12 senior medical teachers to internalize the guideline by writing a chapter on doctor-patient communication, based on their experiences which reflecting on this guideline and international literatures. They also involved these teachers in a workshop of communication skills for other staff-members and 30 Internal Medicine residents. This participative method required six stages in a total of 18 months. We used qualitative and quantitative procedures to collect and analyze the data.

Results: Medical teachers comprehended the information about the introduced guideline but had difficulty in teaching it. There was limited reflection on the guideline they have learned. Internal Medicine residents trained by those medical teachers were more ready for inviting patients' participation. However, the residents communicated unidirectional to the simulated patients.

Conclusion: Introducing a two-way partnership communication guideline to senior medical teachers in a hierarchical culture can be slightly facilitated by a participatory approach. However, this is a slow process hampered by the strong cultural hierarchy which is embedded in all levels of society. 


\section{Chapter 8}

General Discussion 
Figure 8.1 shows the situation with regard to doctor-patient communication in Indonesia, a country in Southeast Asia. This dissertation reports work that was aimed at finding ways to promote mutual understanding and rapport between doctors and patients during consultations. In order to achieve this, a generic guideline was developed, tailored to the Southeast Asian context, which emphasizes specific communication skills that are relevant to Southeast Asian cultural characteristics and takes account of culturally determined barriers to achieving the ideal partnership communication style in doctor-patient encounters.

\section{Interpretation of the research findings}

The current doctor-patient communication style in a Southeast Asian context

The studies in this dissertation show that doctor-patient communication in Southeast Asia is best described as a one-way communication style. Doctors lead the consultation and tend to largely ignore their patients' concerns. An observation study in this thesis, in which doctors, patients, and medical students participated, revealed similar findings of a predominantly paternalistic communication style, thereby confirming the results of previous studies conducted in Asian contexts ${ }^{1-4}$.

Patients' and doctors' perceptions with regard to the current international generic doctor-patient communication guidelines, which emphasize a partnership consultation style

In the interview studies, patients from different educational backgrounds and their doctors indicated that they preferred the partnership communication style during consultations. Similar views have been reported in other studies in non-Western countries $^{5}$. However, opportunities to bring the prevailing one-way communication style closer to the perceived ideal are limited in the Southeast Asian context and culture $^{6,7}$. The key to the limited use of a partnership communication style is that doctors generally have insufficient skills for communicating with patients. 


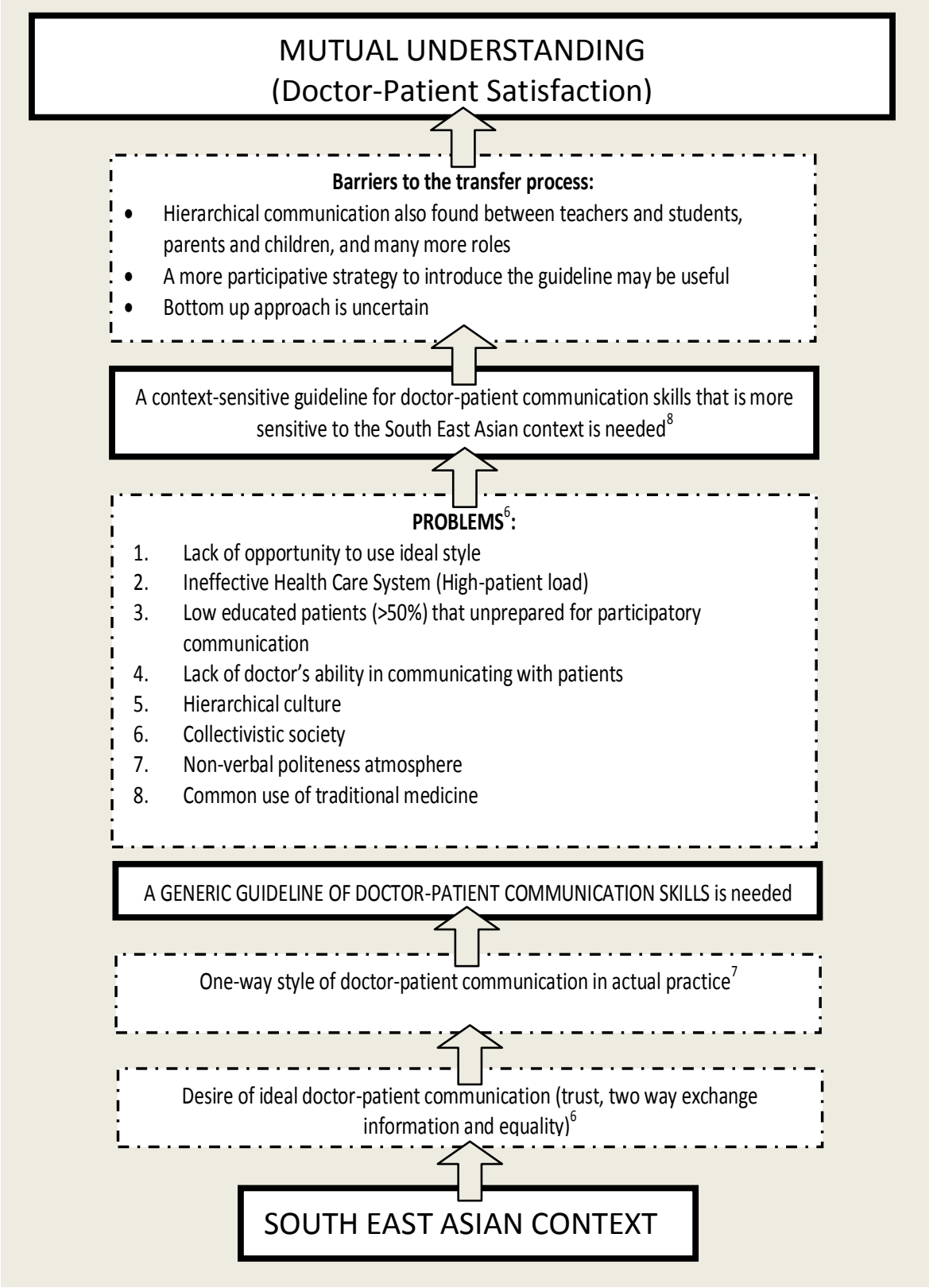

Figure 8.1 A description of the doctor-patient communication situation in Indonesia: Limited opportunities to use an ideal doctor-patient communication style in a South East Asian context with hierarchical culture. 
The studies in this dissertation show that it is important for doctors to become aware that doctors generally have insufficient skills for communicating with patients. Additionally, doctors are generally unaware which cultural characteristics are important to their patients. There is a tendency for doctors to pay less attention to cultural characteristics that are consistent with their patients' expectations, and to adhere to characteristics that widen the gap between doctors and patients. The studies revealed not only a discrepancy between doctors' and patients' perceptions, they also showed that doctors assumed that their approach was generally accepted by the public. The studies in this dissertation show that it is important for doctors to become aware that their patients desire an improved doctor-patient relationship and also that there are essential cultural characteristics that could be helpful in improving that relationship.

A doctor-patient partnership communication guideline that is more suitable for a hierarchical culture should be sensitive to community oriented aspects of decision making, to a climate of strong non verbal politeness, and to the widespread acceptance of traditional medicine.

The studies in this thesis show that both doctors and patients desire a partnership communication style, but that there are cultural factors and gaps between doctors and patients that militate against this ideal. A guideline for doctor-patient communication was developed and validated, which is appropriate for the Southeast Asian context, because it takes into account important cultural factors, notably the strong role of cultural social hierarchy, the involvement of the patient's family and community in decision making, the sensitiveness and responsiveness of the subtle non-verbal politeness in communication, and the common use of traditional medicine ${ }^{8}$. In order to fully grasp the reasons underlying the guideline, doctors need to become aware of the mutual interrelationships between the cultural characteristics that are important to them and to their patients. Non-verbal politeness, for example, tends to widen the hierarchical distance between doctor and patient and can stand in the way of an open relationship built on mutual trust. Demands of non-verbal politeness cause patients to be hesitant to ask questions or express their concerns. Most patients thought their doctor knew more than they did and was therefore above them in the social hierarchy. This inhibited open communication with the doctor, even when they had questions or were dissatisfied. However, non-verbal politeness also influences the doctor's behavior. Doctors may express their willingness to help and their interest in patient's concerns in ways that are too polite and subtle to be recognized by the patient, who may not understand that the doctor is actually inviting him to take an active part in the 
consultation. The cultural mechanism of politeness thus prevents both doctors and patients from communicating effectively, even though this goes against their preferences. The non-verbal politeness and subtleness seem to confirm the importance of superficial relationship among people in Southeast Asia, in order to maintain the harmony and to avoid any conflict ${ }^{8-10}$.

The studies in this thesis revealed that the collectivist society, which is group rather than individual oriented, and in which the community and the family have a central position, affects the influence patients have on decision making about their health care. Another cultural aspect influencing these decisions is the role of traditional medicine, which is highly valued within the community at large. Doctors could incorporate these factors in their decision making by involving the patient's family members, relatives, or even the whole family and the head of the village. At the same time, however, community and family involvement should not lead to neglect of the patient's wishes. Doctors should remain sensitive to patients' individual preferences, and be careful not to ignore their patients' personal consent. Another aspect of a community-oriented culture is its impact on how patients prefer to see their doctors. Patients indicated that they wished to look upon their doctor as a trusted member of the family. Doctors could show their willingness to take on this role by the way they greet their patients. They could address them in the way that is customary in the community, using the appropriate form of address before the name of a young woman, an old man, children, etc $^{11}$. A guideline aimed at promoting a partnership style of communication can be more effective if these cultural characteristics are taken into account. Obviously, doctors would need training to acquire the required skills to be able to take into account the interests of patients and their families during clinical decision making. Involving patients and their families in clinical decision-making would most likely require doctors to pay attention to the use of traditional medicine. Since this is important to most patients, doctors may be able to provide better care when they engage in a discussion about traditional medicine than when they simply disregard its role.

The challenges of introducing a guideline to promote a partnership style of doctorpatient communication that is appropriate for medical teachers in a context with a strong social hierarchical culture.

The introduction to medical teachers of a validated guideline for partnership doctorpatient communication requires a special training strategy. Currently, doctor-patient communication in Southeast Asian contexts is dominated by a one-way paternalistic 
communication pattern ${ }^{6,7}$. This kind of communication is in line with the way people in Southeast Asia interact in their daily lives. Southeast Asian culture is characterized by a strong social hierarchy, although it might not be as pronounced as in a the Southern Asian context ${ }^{1,2}$. The resulting social distance between people influences communication, not only between doctor and patient, but also between teacher and student and even between parents and children and between elder and younger sisters in the same family - as was explained by Geertz, whose ethnographic study was conducted in East Java, Indonesia, more than fifty years ago ${ }^{9}$.

This means that, in introducing a guideline for a partnership style of doctor-patient communication, we deemed it important to consider the academic hierarchical gap between young researcher and senior clinicians by inviting the latter to collaborate in a participative study. However, our ultimate effort to motivate medical teachers to learn our guideline was to ask them to write a chapter for a book on doctor-patient communication that will be published in English and Bahasa Indonesia. Sadly, this idea failed to fully achieve the desired effect. Senior clinicians understood the ideal doctorpatient communication style but had difficulty incorporating it into their daily experiences and their own culture and habits. In other words, they struggled to translate the ideal into practice. This suggests that participative training and interaction do not automatically guarantee quick success in encouraging experienced medical doctors to effectively implement new communication methods. Perhaps participate interaction is more effective when it is learned from a very early age, such as during communication between a child and its caregivers, as was advocated in Vygotksy's "Guided Participation" ${ }^{12}$. Also, reflective thinking skills should ideally be part of a systematic learning process that is initiated long before students enter medical school ${ }^{13}$.

Learning environments that are conducive to participative learning and reflective skills were hard to find in primary and secondary schools in Indonesia during the past decades. Figure 8.2 illustrates the phenomenon of the longitudinal development of interaction patterns between people, and by implication of the one-way interaction pattern between doctors and patients that is at the centre of this dissertation. The one-way style of doctor-patient communication that emerged from the studies in this dissertation is depicted as the 'top of the iceberg'. The largest part of which is submerged under water, representing earlier stages in life when communication style develops and when, in Southeast Asian culture, the one-way style predominates. In the studies, concerns related to social hierarchy were usually more pronounced than any other concerns. The main problem with the strong impact of hierarchical differences 
on the interaction between people is the strong probability that the concerns of those lower in the social hierarchy are not heard, not responded to, and consequently not resolved properly, including real problems that urgently need addressing. To illustrate this, it is quite possible that real health problems in Indonesia have remained unresolved within certain periods due to failed communication between patients and health providers. The typically Indonesian profile of health problems, with malaria, dengue fever, TB/HIV, high maternal and infant mortality, and chronic diseases such as diabetes mellitus and hypertension ${ }^{14}$, should be controllable by adequate education and counseling provided by health professionals. However, if a one-way communication style is used in patient education and counseling, it is questionable whether health providers will really get through to patients, while health providers may not know if patients have really understood what they have been told and whether patients are willing to act in accordance with health providers' recommendations. Perhaps it is simply miscommunication that causes the same health problems to persist in a country for decades.

Time of interaction

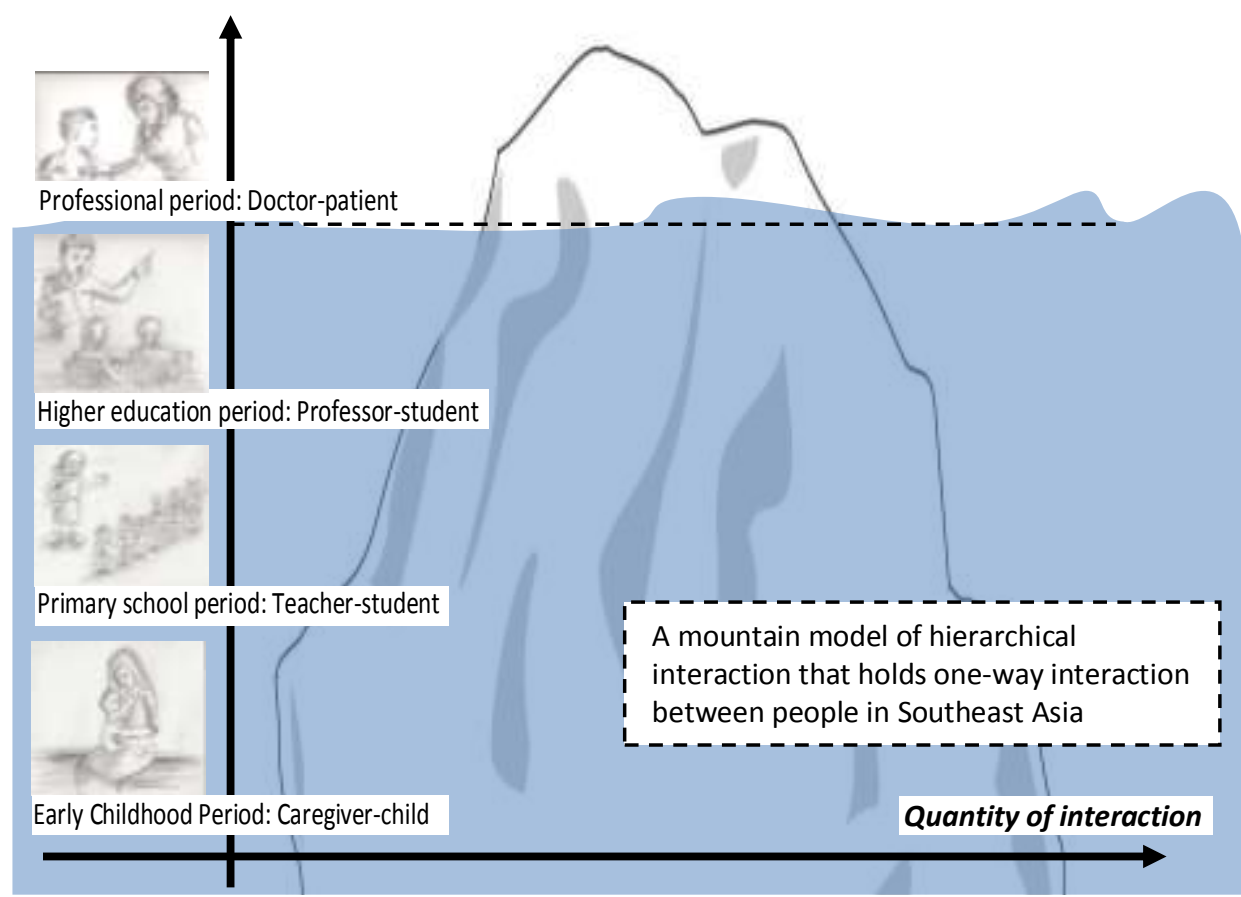

Figure 8.2 A crown of "iceberg phenomenon" of doctor-patient communication and the basis of unequal interaction between people in the context of this dissertation. 


\section{Limitations of this dissertation}

The studies in this dissertation were conducted in internal medicine outpatient clinics. We chose the internal medicine setting because it most closely resembles the primary care setting thereby facilitating both comparison of the newly developed guideline with the Western literature and its adaptation to other clinical situations in Southeast Asia. The training of medical teachers in the use of a guideline for doctor-patient communication especially designed for a Southeast Asian context is still in its early stages. Consequently, there are no outcomes available of studies of the application of the guideline by trained doctors. Once the guideline is fully implemented, such studies will offer valuable opportunities for further research. Another limitation is that the studies in this dissertation did not use an experimental design. This was due to the nature of the subject, which required exploration of relatively unresearched, unspecified, complex, authentic problems. For these problems qualitative and quantitative studies using in-depth interviews, grounded theory methodology and participatory study designs were deemed the most appropriate methods for venturing into the unexplored territory of the "scientific jungle" of doctor-patient interaction in the cultural setting of this dissertation. The studies of this dissertation were conducted in an Indonesian teaching hospital. The cultural characteristics of this setting, comprising the hierarchical social system, community-oriented decision making, nonverbal politeness, and the common use of traditional medicine, resemble those of other Southeast Asian contexts. However, before the results can be generalized to other settings, further studies should be conducted in other specialties and other Southeast Asian settings. We also recommend replication of the studies in other parts of the world in order to gain insight into patients' and doctors' preferences with regard to their mutual communication in different cultural settings.

\section{Further analysis and recommendations for future educational design and research}

In the introduction of this dissertation, it was mentioned that the key tasks of health professionals are establishing the correct diagnosis and providing the correct treatment. Both tasks are performed within health provider-patient interaction processes. We developed a communication guideline tailored to Southeast Asian social cultural characteristics with the aim of promoting a more equal, two-way exchange of information and mutual trust between doctors and patients. We hope that this guideline can help health professionals in Southeast Asia to build closer relationships with their patients. This could also be promoted when doctors would work in one 
community or hospital for an extensive period of time, as opposed to the current situation where doctors may work in three different clinical settings at the same time. This would require a well organized primary health care system and appropriate training of health professionals ${ }^{15}$. The studies showed that patients are highly appreciative of doctors who welcome them as if they are a member of the family. It was also found that doctors who communicate in subtle, indirect and polite ways might fail to convey their well-intentioned efforts to engage patients in a conversation about their health care. It seems that doctors' and patients' very proper politeness may prevent them from attaining the communication ideal they both aspire to. It may therefore be advisable for doctors to be more forthright and expressive in making it clear to patients that they truly want to engage in two-way communication and that patients are indeed very welcome to share their stories and concerns with them. Listening, questioning and reflection skills seem to be the most challenging communication skills to be mastered by health professionals in the Southeast Asian context. Moreover, doctors should be aware of any clinical decision-making that might require family involvement, without abandoning efforts to obtain patients' personal consent. The use of traditional medicine should also be taken into consideration instead of being ignored. Given the importance of the above aspects of doctor-patient communication, as demonstrated in this dissertation, the next challenge for communication skills training will be to train doctors to use shared information and shared decision skills in communicating with patients. In order to apply the recommended communication skills effectively in patient encounters, doctors may need to see patients more than just once. Doctors should initiate several meetings with patients or with patients and other health professionals, such as health volunteers, nurses, nutritionists, midwives, and others. A solid multi-professional education would be the logical next step towards better health care services and patient-safety in Southeast Asia ${ }^{16}$.

Chapter 7 presents the results of attempts to adapt the guideline that was developed for use during brief consultations to meet the needs of doctors with very high patient loads. The guideline was condensed into three word structures: The Greet-InviteDiscuss model, and a further study was conducted to validate this model into interprofession education for patient-safety purpose ${ }^{16}$. Many health professionals participated, doctors, nurses, pharmacists, and dieticians. All health professionals agree that The Greet-Invite-Discuss model can be applied to health professionals other than doctors, with some specific adjustment to its content and examples. Especially for nurses, the guideline was added with the Ready-phase, before Greet phase. For dieticians, the Greet-phase required longer and more extensive interpersonal 
relationship through years with the patients. For pharmacists, the Invite and Discuss phases will be communicated around the rules on how to use the medication. The structure of the guideline was adapted from Indonesian Medical Council and other international guidelines as explained in chapter 7. The Discuss-phase is a notable finding of the guideline that substituted the Explain-phase in the original Indonesian Medical Council guideline for doctor-patient communication. We believe that "discuss"emphasizes more two-way interaction than "explain", to bring the central message of this dissertation in approaching a more partnership communication. By using the same guideline, health professionals agree that Greet-Invite-Discuss can be used for inter-professional communication and education, to provide maximum safety to their patients.

Further recommendation of the study on the Greet-Invite-Discuss model was that a model specifically designed for time-limited circumstances should not be prioritized. The outcome suggested that an effective communication guideline should be sufficiently flexible to be used in any circumstances, including consultations with severe time constraints. This finding is underlined by Lipkin's famous words in the most comprehensive generic guideline of doctor-patient communication: "Effective communication does not need much time" ${ }^{17}$. This point of view is also supported by a randomized controlled trial study among patients with osteoporosis in the Mayo Clinic, US, which demonstrated that proper shared decision making using decision tools led to a significant reduction in consultation time ${ }^{18}$. We therefore recommend that further studies should not explore guidelines for specific circumstances, such as time limited consultations or consultations with patients of a low educational level, but instead focus on more general guidelines that are suitable for many circumstances and conditions, and which are geared to the cultural characteristics of the context in which they are to be applied.

In view of the effects of the top of the iceberg phenomenon in any cultural context, it seems obvious that implementing a guideline promoting a partnership communication style in the context of a strongly hierarchical culture may be easier said than done. Figure 8.2 shows that people learn to use a certain communication style during childhood in the fundamental relationship with caregivers. Consequently, this would seem the best stage to introduce new habits of communication. In our studies, however, we started training of new doctor-patient communication skills at the top of the iceberg, which rests on a solid and extensive basis of quite different communication patterns and also without paying any attention to communication issues arising from the academic hierarchy within the medical profession. It is 
therefore not surprising that we should encounter problems in our attempts to change the way doctors communicate with patients. Finding methods to facilitate the transfer of two-way communication skills to a culturally hierarchical context that intrinsically favors one-way communication will require further systematic studies.

An Indonesian prince who was educated in Holland in the early $20^{\text {th }}$ century; Dewantara, wrote many articles about facilitating learning, advocating participation, feedback, and the importance of reflective thinking ${ }^{19}$. He became the first Minister of Education in Indonesia and received a doctorate honoris causa (honorary degree) from Gadjah Mada University in mid '50s for his significant contribution to the development of ways to facilitate learning within the traditional Indonesian setting. Unfortunately, his learning methods are not easily comprehended by most of today's teachers, since the culturally hierarchical environment promotes social distance between people (more about Dewantara's fundamental and outstanding view of equal relationship between students and teachers in Indonesia - please refer to Appendix). The culture seems to cover up any long term vision of new and unusual - but better - ideas in order to maintain a superficial "cultural harmony". It may seem as if changes are accepted and conflicts and desires resolved, but they are merely hidden underneath a reassuring and comforting outward appearance of harmony ${ }^{8}$. Many more studies in the area of facilitating learning are needed to meet the urgent need revealed in this dissertation for better interaction between Southeast Asian patients and health professionals.

Since 2006, there has been a move towards competence-based education in Indonesian medical education ${ }^{20}$. Students have to master seven competences emphasizing not only medical content but also social behavioral sciences including the ability to apply skills for effective communication, professionalism and lifelong learning. The Indonesian Medical Council declared that in order to train better future doctors, it was essential to acknowledge the importance of not only medical but also social behavioral sciences. However, our study looked at the medical curriculum that was implemented at Gadjah Mada University, and found that most of the learning objectives within the micro curriculum covered only one area of competences, namely mastering medical sciences ${ }^{21}$. The proportion of assessment devoted to other than purely medical competences also evidenced the strong priority of medical sciences over the other competences. Considering that the medical school involved in the study is playing a leading role in the implementation of innovative educational strategies with respect to many other medical schools in Indonesia, we may have to acknowledge that the outcomes of the competence-based curriculum do not differ substantially from those of the previous traditional curriculum. Our study also revealed that clinical 
teachers had difficulty translating ideas from outside the medical competence domains, notably those from social behavioral sciences, into learning strategies for students. This strongly points to the conclusion that before we proceed to train students in social behavioral competences like effective communication and professionalism, it is crucially important to develop and implement teacher training in these areas.

Although change in a Southeast Asian context may be slow, there has already been significant change with regard to doctor-patient communication. We found that today people are willing to talk to researchers about their preference for a partnership doctor-patient communication style. Clearly today's patients are aware that they are unhappy with doctor-patient communication during consultations. Before reaching this stage, they may have gone through stages of change from happy via unhappyunaware to unhappy-aware but silent and afraid to speak about it to anyone. We therefore think that we should use a participatory approach to convey this evidence of change in people's attitudes to the doctors, in order to help them to provide better health care, which in the end will enable them to use their medical expertise more effectively. However, we should also realize that it may take years/decades to successfully achieve results that benefit the whole population. Moreover, change processes in medical education aimed at better doctor-patient communication are unlikely to proceed effectively unless they are supported by a proper faculty development program in doctor-patient communication.

It is encouraging that clear benefits of faculty development have been demonstrated. $A$ review of faculty development that was published in the best evidence in medical education (BEME) series in Medical Teacher in 2006 showed that despite variety in methodologies faculty development programs led to significant changes in attitude, knowledge, and behavior as well as to organizational changes ${ }^{22}$. Although our participatory study did not yield any significant change in one of those areas; as described in Chapter 7, the involvement of the most senior teachers and their initiative to create the Greet-Invite-Discuss guideline specifically for Gadjah Mada University was a remarkable result indeed. It should be taken as a promising sign that a change in the approach to improving communication with patients was initiated by doctors in a culturally hierarchical context.

In order to seek better health provider-patient interaction in the context of Southeast Asia, where the desired type of interaction deviates from the habits that are embedded in the culture, we recommend further studies in the area of communication skills training and faculty development. The research in this dissertation explored 
Southeast Asian expectations regarding better doctor-patient communication and resulted in a guideline for better communication that fits within the social cultural context of Southeast Asian patients. However, there is still a long way to go before the ideal of a partnership approach to communication will be realized. For the ideal, is in many ways, contradictory to the hierarchical culture in which one-way communication seems more natural. This contradiction needs extensive studies and requires a great deal of attention and careful consideration from researchers.

\section{Conclusion}

There are two main conclusions that can be drawn from this dissertation. The first one relates to the finding that in Southeast Asia a partnership communication style is preferred by both doctors and patients although this style should also be sensitive to local cultural characteristics. We therefore recommend a guideline for doctor-patient communication that is suitable for a cultural hierarchic context. The guideline we developed promotes the desired closer relationship between doctor and patient by emphasizing that: doctors should communicate in a way that resembles that of a trusted family member; doctors should involve the family and community without neglecting the patient's individual consent; doctors should be more outspoken in inviting patients to participate in the consultation (during data gathering and education) at the same time sensitive and responsive to patients' non-verbal hesitations; and doctors should acknowledge the use of traditional medicine or any other efforts made by patients and their families following the treatment procedure.

The second conclusion concerns the presence of only minimal learning opportunities for using the desired communication style. Such opportunities are few due to doctors' unawareness of their limited communication skills. This lack of awareness is related to doctors' misperception with regard to the cultural characteristics that are valued by their patients, doctors' limited ability to initiate two-way communication, and doctors' limited ability to reflect on experiences. The huge challenges that are to be overcome in moving towards more effective communication are illustrated by the figure depicting the top of the iceberg phenomenon, which vividly illustrates the extensive and pervasive impact of the fundamental hierarchic culture. In a context where social hierarchy takes natural precedence over any other concerns, the implementation of a new educational design aimed at promoting a partnership communication style can truly be said to be a life challenge. 


\section{References}

1. Moore M. What does patient-centered communication mean in Nepal? Medical Education 2008;42:18-26.

2. Moore M. What do Nepalese medical students and doctors think about patient-centered communication? Patient Education and Counseling 2009;76:38-43.

3. Lee KH, Seow A, Luo N, and Koh D. Attitudes towards the doctor-patient relationship, a prospective study in an Asian Medical School. Medical Education 2008;42:1092-1099.

4. Ohtaki S, Ohtaki T, and Fetters MD. Doctor-patient communication: A comparison between USA and Japan. Family Practice 2003;20(3):276-283.

5. Kiguli S, Mafigiri D, Nakigudde J, van Dalen J, and van der Vleuten CPM. A qualitative study of caregivers' expectations and communication desires during medical consultation for sick children in Uganda. Patient Educ Couns 2010 Aug 23. [E-pub ahead of print] PMID: 20739 13. DOI: 10.1016/j.pec.2010.07.015.

6. Claramita M, Utarini A, Soebono H, van Dalen J, and van der Vleuten CPM. Doctor-patient communication in a Southeast Asian setting: the conflict between ideal and reality. Adv Health Sci Educ 2011;16(1):69-80.

7. Claramita M, van Dalen J, and van der Vleuten CPM. South East Asian doctors and patients are not approaching their perceived ideal partnership style of consultation. Patient Education and Counseling 2011 Feb 9. PII: S0738-3991(11)00112-1. DOI. 10.1016/j.pec.2011.02.002.

8. Claramita M, Prabandari Y, van Dalen J, and van der Vleuten CPM. A guideline for doctorpatient communication more appropriate in South East Asia. A journal manuscript accepted for publication in Southeast Asia Medical Education Journal, 2011.

9. Geertz C. The Religion of Java. Chicago and London: The University Chicago Press, 1976.

10. Raelin JA. Workbased Learning: The new frontier of management development. New Jersey: Prentice Hall, 2000.

11. Iragiliati ES. Utterance Patterns and Politeness Strategies in Indonesian Medical Discourse. A doctoral dissertation submitted to Graduate School of State University Malang. Chicago: ProQuest International, 2006.

12. Wrestch JV. Voices of the Minds: A Socio Cultural Approaches to Mediated Actions. Massachusetts: Harvard Univ Press, 1993.

13. Dreissen E. A Self Critical Doctor. A PhD dissertation. School of Health Professions Education. Maastricht: Maastricht University Press, 2008.

14. Ministry of Health Republic of Indonesia. Profile of Indonesian Health States. Jakarta: Ministry of Health, 2008

15. Gan GL, Azwar A, and Wonodirekso S. A Primer on Family Medicine Practice. Singapore: Singapore International Foundation, 2004.

16. Claramita M, Mariyono S, Huriyati M, and Wahyuningsih MSH. Validation of "Greet-InviteDiscuss" to interprofessional education with primary care doctors, nurses, pharmacists and dieticians. A Senior Lecturer Research Grant report, presented to Faculty of Medicine Gadjah Mada University. Yogyakarta: Faculty of Medicine UGM, 2011.

17. Kurtz S, Silverman J, and Draper J. Teaching and Learning Communication Skills in Medicine. Oxon: Radcliffe Medical Press, 2002.

18. Montori VM, Shah ND, Pencille LJ, and Brenda ME. Use of a Decision Aid to Improve Treatment Decisions in Osteoporosis: The Osteoporosis Choice Randomized Trial. The American Journal of Medicine 2011;124(6):549-556. 
19. Tauchid M, Soeratman, Sajoga, Lahade R.S, Soendoro, and Surjomiharjo A. Articles by Ki Hadjar Dewantara - Book 1 (1st edition). Yogyakarta, Indonesia: Taman Siswa Pub, 1962.

20. Indonesian Medical Council. Standards of Indonesian Medical Doctors' Competences. Jakarta: Indonesian Medical Council, 2006.

21. Claramita M, Sutomo AD, Graber MA, and Scherpbier A. Are patient-centered care values as reflected in teaching scenarios really being taught when implemented by teaching faculty? A discourse analysis on an Indonesian medical school's curriculum. Asia Pacific Family Medicine 2011;10:4.

22. Steinert Y, Mann K, Centeno A, Dolmans D, Spencer J, Gelula M, and Prideaux D. A systematic review of faculty development initiatives designed to improve teaching effectiveness in medical education: BEME Guide No 8. Medical Teacher 2006;28(6):497-526. 
Summary 


\section{Summary}

The aim of this dissertation was to seek approaches to communication and communication training that can promote the actual implementation of a partnership doctor-patient communication style in a Southeast Asian context. For centuries the main tasks of health professionals all over the world have been to identify patients' problems and decide which treatment will be most beneficial. In the mid $20^{\text {th }}$ century, however, it began to be realized that these fundamental tasks take place within the interaction between health professional and patient in so far as the latter is able to communicate. Without this interaction, the two main tasks of health professionals cannot be executed effectively, doctors and patients will not be satisfied, and treatment success may be questionable. Many doctor-patient communication guidelines developed in Western contexts favor a partnership communication style. However, there are no similar guidelines developed specifically for the Southeast Asian context, which differs from the Western context in cultural characteristics, the clinical education environment, and the social and organizational environment in which health care services are delivered.

This dissertation contains eight chapters of reporting research, a summary, a reflection of the author on the PhD process, and acknowledgments.

Chapter 1 introduces the aim of this dissertation. It reviews the main tasks of health professionals and the importance of the interaction between health professionals and patients. Guidelines from Western and non-Western contexts were explored in a literature review, which yielded only few studies that dealt with doctor-patient communication in a Southeast Asian context and no guideline for doctor-patient communication specifically developed for this context. Based on the literature review, four research questions were developed that guided the studies that were conducted to gain insight into issues around the use of a partnership style of doctor-patient communication in a Southeast Asian context. The research questions that directed the studies in this dissertation are: 1 . What is the current doctor-patient communication style in a Southeast Asian context? 2. What are doctors' and patients' perceptions regarding the current generic doctor-patient communication guideline, which emphasizes the partnership consultation style?; 3. What kind of doctor-patient communication guideline would seem more suitable for patients in a Southeast Asian context?; 4. How can a doctor-patient communication guideline tailored to Southeast Asian culture be introduced to medical teachers in that context? 
Chapter two presents a study conducted in an Indonesian teaching hospital comparing doctor-patient communication styles used by medical residents who had and who had not received communication skills training according to an adapted Western guideline during their undergraduate training. The study focused on the current style of doctorpatient communication, i.e. on the first research question. Residents and patients from different clinical departments evaluated doctor-patient communication during consultations. The residents who had taken part in a longitudinal communication skills program were more aware of the shortcomings of their communication skills compared to the residents who had received no communication training. But the study also demonstrated that communication training based on an adapted Western guideline had not been successful in making residents adopt a style that was considered satisfactory by patients. Patients were not satisfied with residents' communication skills, irrespective of residents' prior training.

Chapter three presents qualitative and quantitative studies of doctor-patient communication. The first research question was explored in a study in internal medicine settings in the same Indonesian teaching hospital where the previous study was conducted. Internal medicine residents, patients and medical students answered questions assessing patients' and residents' contributions to the communication during consultations. The second research question was addressed by exploring doctors' and patients' perceptions regarding the partnership communication style in interviews with residents, specialists, patients of different educational levels, and medical students in the same internal medicine settings. All groups of participants indicated that the doctors dominated the communication and that patients' contributions were relatively small. The interviews showed that all participating groups, i.e. residents, patients from different educational backgrounds, and medical students, preferred a partnership communication style that was characterized by trust, equity, and a twoway exchange of information. Three barriers to attaining this ideal were identified. First of all, communication was impacted by time constraints due to doctors' high patient load, caused by the rather unstructured health care system. The second barrier was patients' unpreparedness for a partnership communication style due to the wide educational and social gap between doctors and patients in a country where over half of the population only attends six years of primary school and less than twenty percent attend higher education. The third barrier was doctors' inadequate communication skills due to lack of proper communication skills training. Although the third barrier was not explicitly mentioned by residents, patients, or students its presence was revealed by the qualitative analysis of the interviews. Figure 3.1 in Chapter 3 illustrates 
the conflict between the desired partnership communication style and the rather paternalistic style that was found to prevail in the consultations that were studied.

Chapter four investigates doctor-patient communication in a study in which doctor patient communication during consultations was audio-recorded and analyzed using the Roter Interaction Analysis System (RIAS), an internationally recognized method that has been used in many studies in different countries. We analyzed the interaction between internal medicine residents and patients in internal medicine outpatient clinics. This study revealed that the prevailing communication style was a paternalistic one, thereby supporting the findings of the previous studies and confirming that doctors in an Indonesian teaching hospital did not actually apply the partnership communication style even though they claimed this was the style of preference for them.

Chapter five presents a study exploring which cultural characteristics influenced doctors' and patients' perceptions regarding communication. We interviewed internal medicine residents and internal medicine specialists from the teaching hospital where the earlier studies were conducted and from two other affiliated hospitals and patients with different educational backgrounds. We used the grounded theory methodology to analyze the interviews for emergent cultural factors that appeared to be significant for understanding the perceptions of people in a Southeast Asian context with regard to the partnership style of doctor-patient communication. The aim was to identify characteristics of a Southeast Asian context that could be helpful in developing a communication guideline tailored to this specific context. The analysis revealed eight cultural characteristics, which could be classified as characteristics that widen and characteristics that narrow the social hierarchical distance between people. A remarkable finding was that doctors tended to emphasize cultural characteristics that widened the distance, whereas patients focused on characteristics that narrowed the social gap. These differences in preference between doctors and patients showed the mechanism underlying the dominance of doctors' ideas over those of their patients. A paternalistic communication style prevailed, because doctors emphasized their higher position in the cultural social hierarchy. The study also revealed three characteristics of the clinical and societal environment that favored a paternalistic interaction style: a lack of role models demonstrating a partnership style of doctor-patient communication in the clinical setting, the fact that students do not actively participate in health care during their clinical training, and the traditional agrarian culture, which leads to patients' lack of punctuality in turning up for appointments. 
Chapter six reports the development and validation of a guideline for doctor-patient communication skills based on principles of partnership and enriched with cultural characteristics of the Southeast Asian context. In developing the guideline we used a qualitative approach with in-depth interviews with Southeast Asian communication skills teachers. In order to validate the guideline we performed another qualitative study in which we conducted in-depth interviews with communication skills experts (teachers and researchers) who had published scientific articles on doctor-patient communication in an Asian context. The guideline incorporated cultural characteristics which were considered desirable by Southeast Asian patients and which influenced patients' communication with doctors, and also educational consequences with regard to the specific communication skills required. The strong social hierarchy in Southeast Asia requires health professionals to explicitly encourage patients to engage in twoway communication with them by giving unequivocal (non-verbal) signs that they are willing to help patients, by greeting patients as if they are a family member, and by being alert and prepared to respond to any subtle non-verbal cues from patients. Southeast Asian society is characterized by strong ties within families, among relatives, and within local communities. Health professionals should take account of patients' individual preferences in clinical decision making, but at the same time involve the patient's social environment by inviting family members to contribute to successful clinical decision making, after the patient's consent has been obtained. People in a Southeast Asian culture use very subtle ways to express their concerns, and mostly non-verbal expressions of politeness are a fundamental aspect of communication. Health professionals should be aware that, when a patient nods or says "yes", this does not necessarily imply agreement. It is equally likely that the patient intends to give a polite response to a health professional who is perceived to be of a higher social hierarchic level. Another important cultural characteristic is the widespread acceptance of traditional medicine. Health professionals should master skills of informed and shared decision making in order to properly negotiate with patients about the use of traditional as well as evidence-based medicine.

Chapter seven investigates the introduction to medical teachers of the validated guideline for doctor-patient communication tailored to the Southeast Asian context. An eighteen-month participative study using a combined qualitative and quantitative approach was conducted to facilitate the use of the Southeast Asian guideline by medical teachers in that context. Teachers were invited to write a chapter in a book on doctor-patient communication based on their clinical expertise and the literature. The teachers were also involved in a communication skills workshop for other staff members and internal medicine residents. The chapters written by the teachers were 
analyzed for inclusion of aspects of the guideline described in Chapter 6, and teachers' behavior towards colleagues and residents was observed to examine whether they used a partnership communication style. Residents' perceptions regarding knowledge and behavior were obtained and their communication behavior with simulated patients was observed after participation in the workshop. The results showed that the teachers did comprehend the ideas of the guideline for a partnership style of doctorpatient communication. Nevertheless, in the chapters they wrote they made no explicit mention of the specific Southeast Asian cultural characteristics and only few teachers were able to translate their understanding of the guideline into concrete directions for learning. Furthermore, in communicating with colleagues and residents the teachers mostly used a one-way communication style. The residents evidenced understanding of partnership communication in relation to the use of traditional medicine, but, overall, they used a one-way communication style in encounters with simulated patients of different educational levels.

Chapter eight presents the general discussion of the studies in this dissertation. The research findings are discussed as well as the limitations of the studies, and recommendations are made for the development of an educational design for doctorpatient communication skills training in Southeast Asia. A fundamental barrier to implementing effective training of the skills required for the desired partnership communication style in a culturally hierarchic context is also discussed. This barrier relates to the timing of the introduction of such a style. It is not easy to start learning a communication style that is rather foreign to the cultural setting as late as in higher education. Acquiring such a style requires participative and reflective training, and this should preferably start earlier, at primary and secondary educational levels. If communication skills training that require participative interaction and reflective thinking starts at a higher education level, it can only be successfully implemented if many conditions are met. A crucial condition is commitment from participants and the director of the institution from the very start of the training program and continuing through later stages when a more systematic and structured training design has been developed. Although we developed and validated a guideline for partnership communication between doctor and patient in a Southeast Asian context, studies in the area of communication skills training and the transfer of these skills to clinical practice in Southeast Asia are still in the preliminary stages at this point. Those involved in the development of communication skills training in this context should acknowledge the impact of the fundamental hierarchic culture and the effects of social inequity on interactions between people. Attempts to combine the inherently conflicting styles of participative communication skills training and a culturally 
determined inclination to one-way communication are bound to run into difficulties and those engaged in this process will need perseverance and patience to overcome the challenges. The process of achieving the ideal doctor-patient communication style to which all parties aspire will have to be supported by many further studies in many areas. 
Acknowledgment 


\section{Acknowledgment}

I thank Allah who has chosen Maastricht University for me as the place where I could learn how to be a teacher who can be an inspiration to others. When I first started my $\mathrm{PhD}$ research, I was extremely excited and grateful that I could undertake this project, which showed me a different way of seeing things. Therefore, my gratitude and thanks first and foremost are to the program that has changed my way of thinking, making it more effective and efficient, although I am also aware that I should always consider the different context in which I am working. My gratitude goes to this program, which has been continuously successful in delivering graduates that are fit to be agents of change (I am still trying to discover its "secret" training formula): the Master of Health Professions Education program of Maastricht University, to all the founders of the program, the management team, the teachers, the simulated patients and to my colleagues. I am very grateful that I was given the opportunity to join the master program in 2002-2005, first under the directorship of Professor Henny Boshuizen and then Dr. Jan van Dalen, who were always willing to respond to the needs of their students, even to stupid questions like "what is 'the table of contents'?"

I also wish to express my gratitude to my parents, who have raised me in an atmosphere where we interacted in a way that was different from what was customary in the context and environment where I grew up. I remember when I was little that my parents were always asking themselves whether they were educating me in the right or the wrong way, which was manifested in our everyday discussions in which we shared information and made shared decisions. I have the highest admiration for Professor Cees van der Vleuten, who has shown me his own style of mentorship, which in fact worked out very well for me. The way he was standing on the other side of the bridge, urging me on to cross the bridge by myself until I had made it to the other side. He showed me the highest hill that I could climb and then still different and higher ones which I could conquer to reach my own star. My husband said, "Whoever your supervisor is during your PhD, at the end you will turn out to be somebody just like him". Well, though I may never be quite like Cees, it is because of his example that I now know what it means to be a teacher. I owe a very high debt of gratitude to Professor Hardyanto, who has succeeded in securing a firm position for medical education in our context - a remarkable feat indeed - and who has ensured that I and my colleagues have an equal position to that of our colleagues from other departments. His leadership and his special ability to listen to others' concerns are outstanding; he was and continues to be one of the very few excellent role models in our environment. 
I also wish to express my high appreciation for the doctors and patients who contributed to all my studies and who were willing to share their private communications during consultations for the improvement of interaction between patients and health professionals in the future. My special thanks go to Astrid, Marijke, Fifi, Manik and Doni for their continuous support during my PhD studies. They are friends, colleagues, and teachers to whom I can turn at any time and with whom I can discuss any issue. They are indeed true friends in need. There was limited support for the content of communication skills, which was still a new subject when I started by studies; I therefore thank the many inspiring teachers of whom I mention only a few here: Professor Yati Soenarto, Professor Moetrarsi Kanapsiah, Professor Adi Utarini, Dr. Yayi Suryo, and Dr. Gamayanti.

Many thanks also to Dr. Gerard Majoor for the opportunity of knowing you and working with you on my first paper, the benefits of which continue even today. You guided my first steps as a teacher when I started as a student from a totally different environment. Thanks to Professors: Albert Scherpbier, Job Metsemakers, Mark Graber, David Sattler, Tim Dornan, Jonathan Silverman, Mae Sri Hartati, Rossi Sanusi and Tri Nur Kristina, who showed me the role of facilitator when I worked with them on scientific programs. Although not always directly related to the PhD program, I found many scientific learning opportunities. Many thanks to Dr. Gandes and Dr. Bambang Djarwoto, who gave me every possible support when I was working simultaneously on my PhD thesis and my academic tasks. Without their invaluable help, I would not have managed to combine these two activities. My thanks also to my colleagues in Family Medicine UGM, Proffesor Adi Heru and Dr Wahyudi who offered 'comfortable shelter' for reflecting on my knowledge about medical education within the real context of Indonesian primary-care clinical practice. They helped me see the significance of the rhetorical question: 'what is medical education actually meant for, if not for the sake of better patient care'.

I want to express my high appreciation to Dr. Titi Savitri and Dr. Geraldine, the NPT directors, for their financial decisions, which were always made with the candidate's actual needs in mind. Thank you to Mereke Gorsira for your patience and willingness to help me present my work to the public. Without your significant help, my thoughts would probably never have been made known to others. Thank you Lilian for helping me in so many ways throughout this PhD process. My special thanks to Valerie and Janneke for great discussions and feedback on the many subjects we talked about. Thank you Mickey Chenault, Dr. Nawi, Dr. Novi Akhsaniati, Dr. Anton Soni, Dr. Santi Rini, Dr. Fitriana and Dr. Tyagita for your special review and assistance on statistics. 
Thank you Fajar Wibowo, Patricia Rizkione, Bayu, Windy, Tamy, and other students who showed a special interest in learning more about communication skills and who helped me with my projects. I hope you will have gained what you hoped for by studying this subject.

Many thanks also to the Thissen family and Dr. Angenies who provided us with excellent accommodation at an affordable price while we were in Maastricht. It is wonderful to know the way Dutch people live in a real Dutch house; it has given us a real 'ambiance nuance'. Thank you Mrs. Fatimah, who helped taking care of my children in Yogya every day. I can feel that my children feel your endless love.

Lovely thanks to Faisal, Karina, and Farrah, who were there for me in sickness, tears, and happiness from the beginning of the project to the very end. I imagine that Faisal, coming from a background that represents the hierarchical culture I describe in my studies, must have had a hard time following discussions with me; but he has been there for me all the time and he has never given up learning together with me. There was a time when I thought this study should not have been undertaken at this stage of my life, because I should have dedicated this stage to my children. However, by combining this distance learning program with holidays, I hope that I will have inspired them to pursue their own dreams in the future, whatever they may be. I just wonder whether it might not have been better for the children if this had been a full time program. Children who have the opportunity to live in a different context may be more sensitive to different ideas and cultures and therefore more open to new learning experiences for their future.

And I shall thank Alamsyah, welcome to the world, son! You are a special gift at the end of my PhD that I never ever dare to dream to have you here. A son may continue a family name, but you have more important thing to do, Son: Reach your dream! 
Curriculum Vitae 


\section{Curriculum Vitae}

Mora Claramita was born on 2 August 1974 in Yogyakarta, central Java, Indonesia. Her father was a dentist and her mother was a lecturer in biology. She attended primary and secondary education in Yogyakarta and entered Gadjah Mada University in the same town as a medical student. She graduated as one of the top ten medical doctors in 2000, and two years later undertook the MHPE program supported by a STUNED scholarship from the Netherlands embassy. Her first experience of being abroad was in Japan, where she joined a student exchange program sponsored by JICA in 1996. She joined The $17^{\text {th }}$ Network conference in Mexico City, 1997, where she presented a study on communication skills. It was here that she first saw the brochure of the MHPE program. As a result of her presentation at the Network conference, the Rector of Gadjah Mada University invited her to a "Dies Natalis" ceremony with other special invited lecturers and honoured students. At this ceremony, she met Faisal, whom she later married, and who is now an associate professor in Geotechnical Engineering at the same university. She lived in Japan for three years, when her husband was a PhD student, and it was during that time that she finished her MHPE distance learning program. Her first daughter Karina was born in Tokyo. She was appointed a full time staff member at Gadjah Mada Medical School after she finished the MHPE program in 2005 , with merit. She is currently engaged in teaching, research and service in the Skills Laboratory, which is now part of the Medical Education Department. Her great passion is interaction between health professionals and their patients, and she has devoted many of her studies to the topics of doctor-patient communication and community based education. After finishing her PhD, she would like to continue her work as a researcher in the Medical Education Department and establish a proper educational program in primary care, which is lagging behind in educational development compared to training programs in many medical specialties in Indonesia. She has been practicing in general primary practice since 2000 at the UGM Clinic and at a clinic for breast and cervical cancer screening: Kucala Medical Centre in Yogyakarta. 
SHE Dissertations Series 


\section{SHE Dissertations Series}

In the SHE Dissertation Series, dissertations are published of PhD candidates from the School of Health Professions Education (SHE) who defended their PhD thesis at Maastricht University. The most recent ones are listed below. For more information go to: www.maastrichtuniversity.nl/she.

Stalmeijer, R. E. (07-07-2011) Evaluating Clinical Teaching through Cognitive Apprenticeship.

Veldhuijzen, J.W. (17-06-2011) Challenging the patient-centred paradigm: designing feasible guidelines for doctor patient communication.

Van Blankenstein, F. (18-05-2011) Elaboration during problem-based, small group discussion: A new approach to study collaborative learning.

Van Mook, W. (13-05-2011) Teaching and assessment of professional behavior: Rhetoric and reality.

De Leng, B. (8-12-2009). Wired for learning. How computers can support interaction in small group learning in higher education.

Maiorova, T. (29-05-2009). The role of gender in medical specialty choice and general practice preferences.

Bokken, L. (04-03-2009). Innovative use of simulated patients for educational purposes.

Wagenaar, A. (18-09-2008). Learning in internships. What and how students learn from experience.

Driessen, E. (25-06-2008). Educating the self-critical doctor. Using portfolio to stimulate and assess medical students' reflection.

Derkx, H. (18-06-2008). For your ears only. Quality of telephone triage at out-of-hours centres in the Netherlands.

Niessen, Th. (30-11-2007). Emerging epistemologies: making sense of teaching practice.

Budé, L. (05-10-2007). On the improvement of students' conceptual understanding in statistics education.

Niemantsverdriet, S. (26-07-2007). Learning from international internships: A reconstruction in the medical domain.

Marambe, K. (20-06-2007). Patterns of student learning in medical education - A Sri Lankan study in traditional curriculum.

Pleijers, A. (19-01-2007). Tutorial group discussion in problem-based learning.

Sargeant, J. (21-09-2006). Multi-source feedback for physician learning and change.

Dornan, T. (12-06-2006). Experience-based learning.

Wass, V. (12-05-2006). The assessment of clinical competence in high stakes examinations.

Prince, K. (21-04-2006). Problem-based learning as a preparation for professional practice. 
